\title{
\begin{tabular}{l|l} 
Mitraries & DSpace@MIT
\end{tabular}
}

\author{
MIT Open Access Articles
}

Metal-Based Optical Probes for Live Cell Imaging of Nitroxyl (HNO)

The MIT Faculty has made this article openly available. Please share how this access benefits you. Your story matters.

Citation: Rivera-Fuentes, Pablo, and Stephen J. Lippard. “Metal-Based Optical Probes for Live Cell Imaging of Nitroxyl (HNO)." Accounts of Chemical Research 48.11 (2015): 2927-2934.

As Published: http://dx.doi.org/10.1021/acs.accounts.5b00388

Publisher: American Chemical Society (ACS)

Persistent URL: http://hdl.handle.net/1721.1/107934

Version: Author's final manuscript: final author's manuscript post peer review, without publisher's formatting or copy editing

Terms of Use: Article is made available in accordance with the publisher's policy and may be subject to US copyright law. Please refer to the publisher's site for terms of use. 


\section{Metal-Based Optical Probes for Live Cell Imaging of Nitroxyl (HNO)}

Pablo Rivera-Fuentes and Stephen J. Lippard*

Department of Chemistry, Massachusetts Institute of Technology, Cambridge, MA 02139

KEYWORDS: Nitroxyl, copper complexes, fluorescent sensors, live-cell imaging, multicolor microscopy

Conspectus: Nitroxyl (HNO) is a biological signaling agent that displays distinctive reactivity compared to nitric oxide (NO). As a consequence, these two reactive nitrogen species trigger different physiological responses. Selective detection of $\mathrm{HNO}$ over $\mathrm{NO}$ has been a challenge for chemists, and several fluorogenic molecular probes have been recently developed with that goal in mind. Common constructs take advantage of the HNO-induced reduction of $\mathrm{Cu}(\mathrm{II})$ to $\mathrm{Cu}(\mathrm{I})$. The sensing mechanism of such probes relies on the ability of the unpaired electron in a $d$ orbital of the $\mathrm{Cu}(\mathrm{II})$ center to quench the fluorescence of a photoemissive ligand by either an electron or energy transfer mechanism. Experimental and theoretical mechanistic studies suggest that proton-coupled electron transfer mediates this process, and careful tuning of the copper coordination environment has led to sensors with optimized selectivity and kinetics.

The current optical probes cover the visible and near-infrared regions of the spectrum. This palette of sensors comprises structurally and functionally diverse fluorophores such as coumarin 
(blue/green emission), boron dipyrromethane (BODIPY, green emission), benzoresorufin (red emission), and dihydroxanthenes (near-infrared emission). Many of these sensors have been successfully applied to detect HNO production in live cells. For example, copper-based optical probes have been used to detect HNO production in live mammalian cells that have been treated with $\mathrm{H}_{2} \mathrm{~S}$ and various nitrosating agents. These studies have established a link between HSNO, the smallest $S$-nitrosothiol, and HNO. In addition, a near-infrared HNO sensor has been used to perform multicolor/multianalyte microscopy, revealing that exogenously applied HNO elevates the concentration of intracellular mobile zinc. This mobilization of zinc ions is presumably a consequence of nitrosation of cysteine residues in zinc-chelating proteins such as metallothionein.

Future challenges for the optical imaging of HNO include devising probes that can detect HNO reversibly, especially because ratiometric imaging can only report equilibrium concentrations when the sensing event is reversible. Another important aspect that needs to be addressed is the creation of probes that can sense HNO in specific subcellular locations. These tools would be useful to identify the organelles in which HNO is produced in mammalian cells and probe the intracellular signaling networks in which this reactive nitrogen species is involved. In addition, near-infrared emitting probes might be applied to detect HNO in thicker specimens, such as acute tissue slices and even live animals, enabling the investigation of the roles of $\mathrm{HNO}$ in physiological or pathological conditions in multicellular systems.

\section{Introduction: Design of Metal-Based Probes for HNO}

Nitroxyl (HNO) is the one-electron reduced, protonated derivative of nitric oxide (NO). The chemistry and therefore the physiological and pathological effects of HNO are considerably 
different from those of NO. ${ }^{1}$ Detecting HNO in biological systems is a challenge that has caught the attention of chemists. Difficulties associated with HNO sensing include differentiation from NO and other biologically relevant analytes, rapid detection of low concentrations, and compatibility of the sensing mechanism with biological environments, in particular, neutral or slightly acidic $\mathrm{pH}$, high ionic strength, and a temperature of $37^{\circ} \mathrm{C}$.

An efficient strategy for detecting HNO is to take advantage of its redox activity. ${ }^{2}$ Probes that can be reduced selectively by HNO serve as sensors if an appropriate output signal is linked to the reduction step. Although there are other chemical reactions that can be used to detect and trap $\mathrm{HNO}^{3}$ we focus here on systems that juxtapose a $\mathrm{Cu}(\mathrm{II})$ coordination complex with a fluorophoric moiety. The sensing mechanism of such probes relies on the ability of the unpaired electron in a $d$ orbital of the $\mathrm{Cu}(\mathrm{II})$ center to quench the fluorescence of a photoemissive ligand by either electron or energy transfer (Scheme 1). Reduction of $\mathrm{Cu}(\mathrm{II})$ to $\mathrm{Cu}(\mathrm{I})$ by $\mathrm{HNO}$ fills the $d$ manifold, restoring the fluorescence of the ligand.

Scheme 1. General mechanism of HNO sensing using copper complexes. ${ }^{a}$
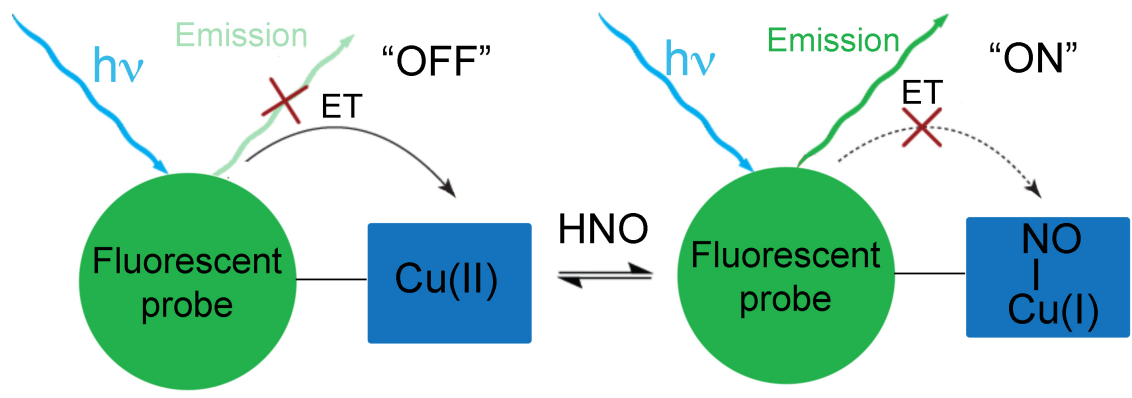

${ }^{\text {a }} \mathrm{The} \mathrm{Cu}$ (II) complex is paramagnetic and electron transfer (ET) from the photoexcited state of the fluorophore to the metal center quenches the fluorescence of the probe (OFF state). Selective reduction of $\mathrm{Cu}(\mathrm{II})$ to $\mathrm{Cu}(\mathrm{I})$ by $\mathrm{HNO}$ abolishes ET, restoring the emission of the fluorophore (ON state). 
An early example of this kind of probe is a conjugated metallopolymer doped with $\mathrm{Cu}(\mathrm{II}) .{ }^{4} \mathrm{The}$ polymer comprises bithiophene, phenylene, and dipyridine units that are functionalized with hydrophilic side chains to enhance its water solubility. ${ }^{4}$ This polymer absorbs light at $\lambda_{\mathrm{abs}}=446$ $\mathrm{nm}$ and emits at $\lambda_{\mathrm{em}}=485 \mathrm{~nm}$ in aqueous buffer (50 mM HEPES, $100 \mathrm{mM} \mathrm{KCl}, \mathrm{pH} 7.4$ ). Addition of $\mathrm{CuSO}_{4}$ induces a 10-fold decrease in fluorescence, consistent with binding of paramagnetic $\mathrm{Cu}(\mathrm{II})$ ions. Whereas treatment of the metallopolymer with $\mathrm{NO}$ does not significantly increase the fluorescence of the complex, addition of Angeli's salt $\left(\mathrm{Na}_{2} \mathrm{~N}_{2} \mathrm{O}_{3}\right)$, an HNO donor, ${ }^{5}$ results in a modest, 2.1-fold fluorescence turn-on. Although the polymer has not been applied in a biological study, it exemplifies the $\mathrm{Cu}(\mathrm{II}) / \mathrm{Cu}(\mathrm{I})$ reduction approach to $\mathrm{HNO}$ sensing.

\section{Fluorescent Sensors Based on Copper Complexes of Triazolyl(dipicolyl)amine Ligands}

In 2010 Rosenthal and Lippard reported a small-molecule fluorescent sensor for HNO. ${ }^{6}$ The probe, termed CuBOT1, is a boron dipyrromethane (BODIPY) fluorophore linked to a tripodal $\mathrm{Cu}$ (II) complex. The $\mathrm{Cu}$ (II) binding unit is connected to BODIPY via copper-catalyzed azide-

alkyne Huisgen cycloaddition (Scheme 2). ${ }^{7,8}$ Yao and co-workers subsequently utilized this efficient strategy to synthesize a similar probe based on a coumarin dye, called CuCOT $1,{ }^{9}$ which has properties that are similar to those of CuBOT1 (Scheme 2). In both cases, the probes have a triazole linkage that participates in metal binding and keeps the fluorophore in close proximity to the paramagnetic ion. 
Scheme 2. Synthesis and photophysical properties of fluorescent HNO sensors BOT1 and COT1 obtained by click chemistry. ${ }^{a}$
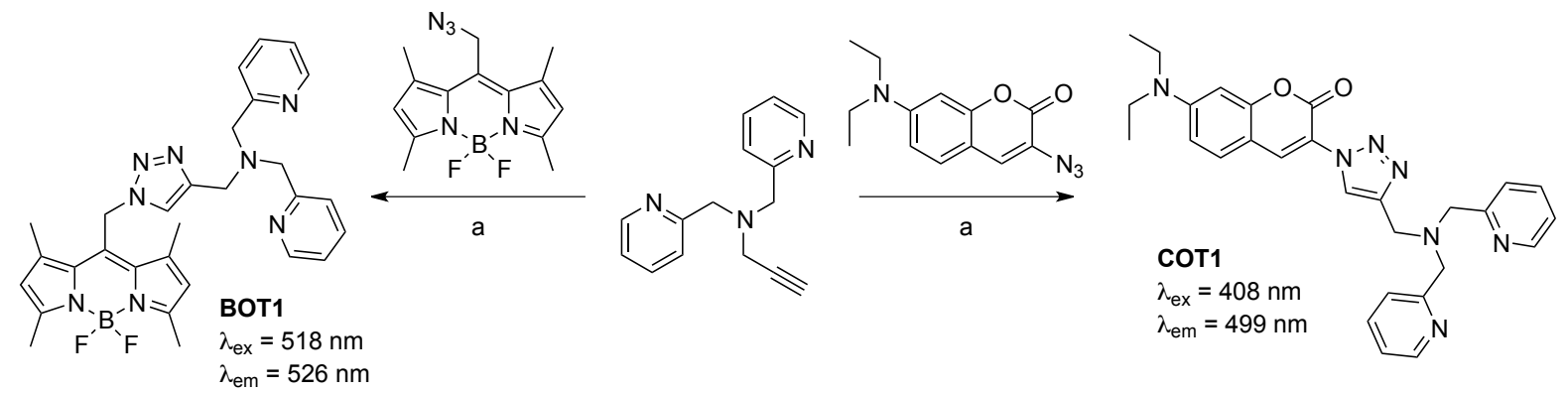

${ }^{\text {a} R e a g e n t s ~ a n d ~ c o n d i t i o n s ; ~ a) ~} \mathrm{CuSO}_{4}$, ascorbic acid, $\mathrm{MeOH}(\mathrm{BOT} 1 ; 84 \%)$ or $\mathrm{H}_{2} \mathrm{O} / \mathrm{EtOH}(\mathrm{COT} 1$; 63)

The metal-free ligand BOT1 absorbs light at $\lambda_{\text {abs }}=518 \mathrm{~nm}\left(3.1 \times 10^{4} \mathrm{M}^{-1} \mathrm{~cm}^{-1}\right)$ in aqueous buffer (50 mM PIPES, $100 \mathrm{mM} \mathrm{KCl}, \mathrm{pH} 7.0)$. The ligand emits at $\lambda_{\mathrm{em}}=526 \mathrm{~nm}(\phi=0.12)$ under the same conditions. Titration of ligand BOT1 with $\mathrm{CuCl}_{2}$ reveals a dissociation constant of $K_{\mathrm{d}}=3$ $\mu \mathrm{M}$. Binding of $\mathrm{Cu}(\mathrm{II})$ induces a dramatic decrease in the fluorescence intensity of BOT1 $(\phi=$ 0.01). In addition, the lifetime of the photoexcited state of the ligand decreases 30 -fold upon $\mathrm{Cu}$ (II) binding, indicating that this probe might also be useful for fluorescence lifetime imaging microscopy (FLIM). ${ }^{10}$ Treatment of the probe with 10 equiv of Angeli's salt in aqueous buffer leads to a 4-fold enhancement of the fluorescence after only $5 \mathrm{~min}$, demonstrating that this copper-based probe responds rapidly to HNO. The enhancement of the fluorescence intensity of CuBOT1 depends on the amount of Angeli's salt added. When the probe is treated with 100 or 1000 equiv, the maximum fluorescence turn-on response is 10 - and 14 -fold, respectively. ${ }^{11}$ This behavior can be explained by considering that, under neutral conditions, some of the HNO derived from Angeli's salt can dimerize and dehydrate rapidly to form nitrous oxide $\left(\mathrm{N}_{2} \mathrm{O}\right){ }^{2}$ therefore, an excess of Angeli's salt is required to completely turn on the fluorescence of the probe. 
Ligand COT1 displays photophysical properties that are also suitable for live-cell optical microscopy. ${ }^{9}$ In the metal-free state, COT1 displays an absorption maximum at $\lambda_{\text {abs }}=400 \mathrm{~nm}$ $\left(8.1 \times 10^{4} \mathrm{M}^{-1} \mathrm{~cm}^{-1}\right)$ and emits at $\lambda_{\mathrm{em}}=499 \mathrm{~nm}(\phi=0.63)$. Chelation of $\mathrm{Cu}(\mathrm{II})$, which occurs with a $K_{\mathrm{d}}=1.2 \mu \mathrm{M}$, decreases the fluorescence of COT1 by 24-fold. It is not entirely clear why CuCOT1 displays a larger turn-on compared to CuBOT1, but one possible reason is that ligand COT1 emits light with a greater quantum yield $(\phi=0.63)$ in the metal-free state compared to $\operatorname{BOT} 1(\phi=0.12)$.

Both CuBOT1 and CuCOT1 seem to detect HNO based on the same mechanism. The reaction between these $\mathrm{Cu}(\mathrm{II})$ complexes and $\mathrm{HNO}$ resembles the reversible interconversion of $\mathrm{HNO}$ and NO mediated by the enzyme superoxide dismutase 1 (SOD1). ${ }^{12}$ Gas chromatography coupled to mass spectrometry (GC-MS) confirmed that NO evolves as a gas from the reaction between CuBOT1 and Angeli's salt, which strongly suggests that HNO reacts with the $\mathrm{Cu}(\mathrm{II})$ center to generate $\mathrm{NO}$ and $\mathrm{Cu}(\mathrm{I}){ }^{6}$ This mechanism is further supported by electron paramagnetic resonance (EPR) studies of both CuBOT1 and CuCOT1, which reveal that the signal of the $\mathrm{Cu}(\mathrm{II})$ complex is abolished upon reaction with Angeli's salt under anaerobic conditions, confirming reduction to the diamagnetic ion $\mathrm{Cu}(\mathrm{I}){ }^{6,9}$

The selectivity of CuBOT1 and CuCOT1 toward HNO is similar. Both probes detect HNO selectively over NO and $S$-nitrosothiols such as $S$-nitroso cysteine (SNOC) ${ }^{6,9}$ Other reactive nitrogen species such as $\mathrm{NO}_{3}^{-}, \mathrm{NO}_{2}^{-}$, and $\mathrm{ONO}_{2}^{-}$also do not interfere with $\mathrm{HNO}$ detection, and the probes are impervious to the biological oxidizing agents $\mathrm{H}_{2} \mathrm{O}_{2}$ and $\mathrm{ClO}^{-}$. The selectivity of CuBOT1 for HNO over NO and other reactive nitrogen species can be explained based on its reduction potential. In phosphate-buffered saline (PBS) at $\mathrm{pH} 7.4, \mathrm{CuBOT} 1$ has a reduction 
potential of $+0.16 \mathrm{~V}$ (vs NHE).$^{11}$ Under equivalent conditions, the oxidation potential of HNO is $-0.11 \mathrm{~V}$ (vs NHE) ${ }^{13}$ and therefore the reduction of $\mathrm{Cu}(\mathrm{II})$ to $\mathrm{Cu}(\mathrm{I})$ in BOT1 is thermodynamically favored. In contrast, oxidation of $\mathrm{NO}$ to give the nitrosonium cation $\mathrm{NO}^{+}$occurs at $1.52 \mathrm{~V}$ (vs NHE) $)^{14}$ and therefore NO is not able to reduce CuBOT1.

A limitation of both CuBOT1 and CuCOT1 is that reducing agents of biological origin such as cysteine and ascorbic acid can induce fluorescence turn-on. ${ }^{6.9}$ In the case of CuBOT1, cysteine restores the fluorescence of ligand BOT1 owing to reduction of $\mathrm{Cu}(\mathrm{II})$. Similar results were obtained when CuCOT1 was treated with either cysteine or ascorbic acid. Overcoming the sensitivity of copper-based probes toward thiols is challenging because they are often better reducing agents than $\mathrm{HNO}$.

The creation of better fluorescent sensors can be guided by mechanistic investigations of known probes. The reaction between HNO and CuBOT1 has been studied computationally. ${ }^{15}$ The starting species in the calculated intrinsic reaction coordinate (IRC) is CuBOT1 with a molecule of HNO bound as fifth ligand (Figure 1). The transition state of the reaction has an energy of 12 $\mathrm{kcal} \mathrm{mol}^{-1}$ and involves hydrogen abstraction from HNO by the triazolyl segment of the ligand. Deprotonation of HNO is most probably accomplished by nitrogen 3 (N3) of the triazole and is accompanied by elongation of the N3-Cu bond from $2.08 \AA$ in the starting structure to $3.16 \AA$ in the transition state. Moreover, the spin density localized around NO increases from 0.099 electrons in the starting structure to 0.258 electrons in the transition state. A change in spin density is also observed at the copper center, decreasing from $\sim 1$ to 0.43 electrons in the transition state. These results suggest that proton-coupled electron transfer (PCET) is the operative mechanism in the reaction between CuBOT1 with HNO. The transition state leads to an intermediate with protonated triazole and copper-bound NO. At this stage of the reaction, 
$95 \%$ of all spin density is localized around the coordinated NO molecule, confirming that reduction of $\mathrm{Cu}$ (II) to $\mathrm{Cu}(\mathrm{I})$ is indeed coupled to abstraction of a proton. This intermediate can subsequently release NO gas, which has been observed experimentally. ${ }^{6}$

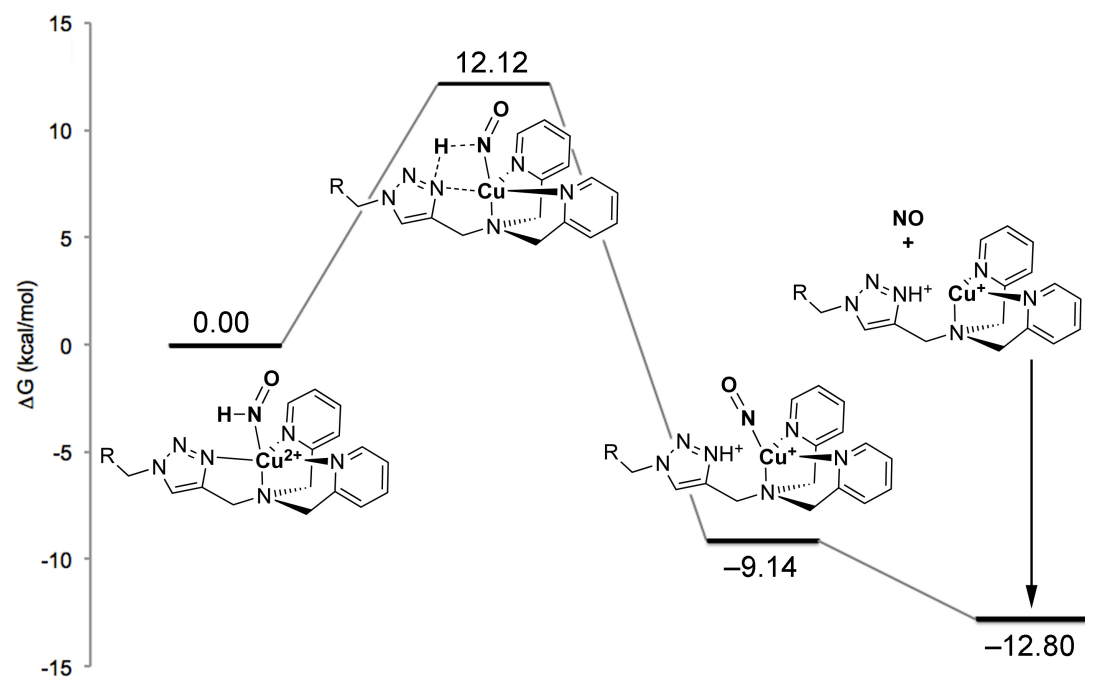

Figure 1. Proposed mechanism of the reaction of CuBOT1 with HNO. Relative free energies were obtained at the mPW1PW91/6-311++G(2d,2p)/LANL2DZ level of theory.

An important conclusion that can be drawn from this mechanistic study is that, by increasing the basicity of the triazolyl fragment, it might be possible to enhance the rate of PCET. Amine-based ligands that are more basic than triazole might therefore provide sensors that are faster and more sensitive, and perhaps such a structural modification will help establish a kinetic preference for the oxidation of HNO over other biological reducing agents.

\section{Biological Applications of CuBOT1}

CuBOT1 was the first fluorescent probe to be successfully applied for detection of HNO in live cells. ${ }^{6}$ The compound readily permeates the plasma membrane of mammalian cells, and incubation of live HeLa cells with $1 \mu \mathrm{M}$ of the probe for $1 \mathrm{~h}$ at $37^{\circ} \mathrm{C}$ was sufficient to load the 
molecule to the intracellular space. ${ }^{6}$ Treatment of these cells with $150 \mathrm{mM}$ Angeli's salt led to an increase in intracellular fluorescence over the course of $5 \mathrm{~min}$ (Figure 2). As observed in cuvettes, treatment of the cells with NO donors did not increase the fluorescence significantly over the same period of time.

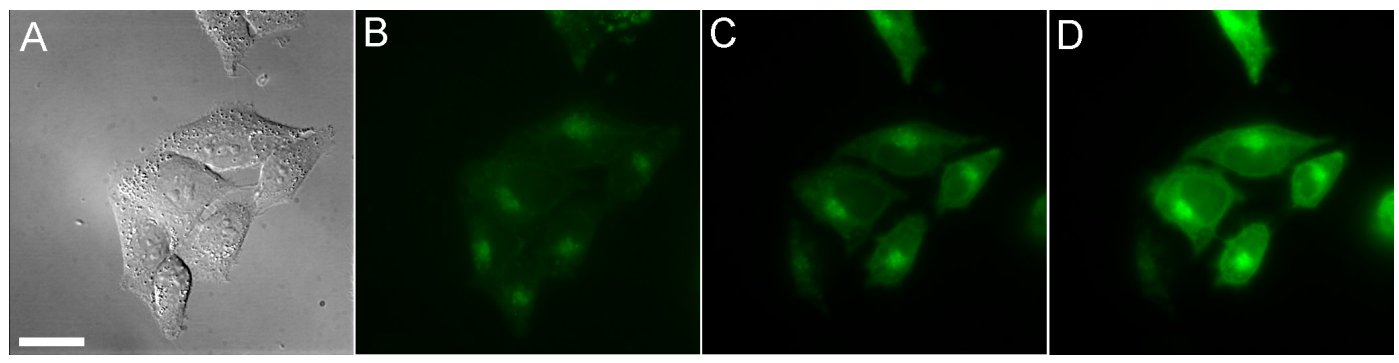

Figure 2. Time-dependent fluorescence turn-on of CuBOT1 in live HeLa cells treated with Angeli's salt. A) Differential interference contrast (DIC) image; B) $0 \mathrm{~min}, \mathrm{C}$ ) $1 \mathrm{~min}$, and D) 5 min after treatment with $150 \mathrm{mM}$ Angeli's salt. Scale bar $=25 \mu \mathrm{m}$.

The subcellular distribution of CuBOT1 was investigated in live HeLa cells. ${ }^{11}$ In three separate sets of experiments, live cells were co-incubated with CuBOT1 and commercial fluorescent markers for mitochondria, endoplasmic reticulum (ER), or the Golgi apparatus. The colocalization of CuBOT1 with these organelle markers was evaluated by calculating a Pearson's correlation coefficient $\left(R_{\mathrm{P}}\right)^{16}$ of the green signal of CuBOT1 and the red or blue signal of the marker. Whereas CuBOT1 did not seem to accumulate significantly in mitochondria $\left(R_{\mathrm{P}}=0.12\right.$; $R_{\mathrm{P}}=1:$ perfect correlation, $R_{\mathrm{P}}=0$ : no correlation, and $R_{\mathrm{P}}=-1$ : anticorrelation), ${ }^{16}$ the probe showed moderate correlation with markers in the ER $\left(R_{\mathrm{P}}=0.51\right)$ and Golgi $\left(R_{\mathrm{P}}=0.62\right) .{ }^{11}$ These experiments demonstrate that CuBOT1 does not exclusively target a cellular organelle.

Although the direct observation of endogenously produced HNO in mammalian cells has remained elusive, CuBOT1 was able to demonstrate the generation of $\mathrm{HNO}$ in live cells that 
have been treated with specific reagents. An example is the synthesis of HNO from HSNO, the smallest nitrosothiol. ${ }^{17}$ This species is a putative precursor of HNO in biological systems and can be produced under physiologically relevant conditions by transnitrosation of $S$-nitrosothiols and $\mathrm{H}_{2} \mathrm{~S} .{ }^{17}$ In the presence of excess $\mathrm{H}_{2} \mathrm{~S}$, HSNO can react further to produce $\mathrm{HNO}$ and $\mathrm{H}_{2} \mathrm{~S}_{2}$. $\mathrm{HSNO}$ may therefore play a role in biological systems as a membrane-permeable carrier of $\mathrm{NO}^{+}$or $\mathrm{NO}^{-17}$

CuBOT1 was also used to investigate the generation of HNO from the $S$-nitrosothiol GSNO and $\mathrm{H}_{2} \mathrm{~S} .{ }^{17}$ Human umbilical vein endothelial cells (HUVECs) were incubated with $10 \mu \mathrm{M}$ CuBOT1 for $20 \mathrm{~min}$ followed by treatment with NO donors did not lead to any enhancement of fluorescence. Incubation of the cells with $\mathrm{H}_{2} \mathrm{~S}$ only increased the fluorescence of CuBOT1 slightly. In contrast, when cells loaded with CuBOT1 were treated for 20 min with GSNO and then $\mathrm{H}_{2} \mathrm{~S}$, strong fluorescence turn-on was observed. This result indicates either that HNO is being produced or that HSNO also induces fluorescence turn-on of CuBOT1.

In related work, Ivanović-Burmazović and co-workers showed that sodium nitroprusside $\left(\mathrm{Na}_{2}\left[\mathrm{Fe}(\mathrm{CN})_{5}(\mathrm{NO})\right]\right.$; SNP) reacts in live cells to produce HNO. ${ }^{18}$ In this study, the authors employed CuBOT1-loaded HUVECs to show that treatment of these cells with either SNP or $\mathrm{H}_{2} \mathrm{~S}$ alone did not elicit a significant fluorescence turn-on. When the cells were incubated with CuBOT1 followed by a mixture of SNP and $\mathrm{H}_{2} \mathrm{~S}$, however, intracellular fluorescence indicative of reduced CuBOT1 was observed, suggesting that HNO was produced.

Filipovic and co-workers investigated the production of HNO from nitrite in HUVECs upon treatment with $\mathrm{H}_{2} \mathrm{~S} .{ }^{19} \mathrm{CuBOT} 1$ is relatively insensitive to both nitrite and $\mathrm{H}_{2} \mathrm{~S}$ in live cells, which makes it suitable for studying the hypothesis that $\mathrm{H}_{2} \mathrm{~S}$ is a reducing agent that can facilitate the 
conversion of nitrite into HNO catalyzed by heme iron centers..$^{20}$ The authors loaded CuBOT1 into HUVECs and treated them with both nitrite and $\mathrm{H}_{2} \mathrm{~S}$, which led to fluorescence turn-on of CuBOT1. ${ }^{19}$ Treating the cells separately with either nitrite or $\mathrm{H}_{2} \mathrm{~S}$ induced no enhancement of fluorescence. This study suggests that $\mathrm{H}_{2} \mathrm{~S}$-mediated reduction of nitrite is a viable biosynthetic pathway to HNO.

Recent work led by the Filipovic group also used CuBOT1 to investigate signaling pathways of $\mathrm{HNO}^{21}$ The sensor was employed to detect the presence of intracellular HNO in neurons that were treated with Angeli's salt. A major conclusion of this work, which included many other experiments, is that HNO activates calcium influx in sensory neurons by forming disulfide bonds in the transient receptor potential channel A1 (TRPA1). ${ }^{22}$ Activation of TRPA1 by HNO leads to release of calcitonin gene-related peptide (CGRP), which is an established biomarker of HNO signaling. ${ }^{23}$

\section{Benzoresorufin-based Copper Complexes for Detection of HNO and NO}

CuBOT1 has been useful for cell microscopy studies of HNO but its relatively short emission wavelength $\left(\lambda_{\mathrm{em}}=526 \mathrm{~nm}\right)$ is a limitation for imaging thicker specimens such as acute tissue or live animals. ${ }^{24}$ Probes that emit at longer wavelengths are also useful for multicolor imaging experiments, in which two or more analytes can be monitored simultaneously. ${ }^{25,26}$ Paramagnetic $\mathrm{Cu}(\mathrm{II})$ ions are efficient quenchers of fluorescence in the visible and near-infrared (NIR) region of the spectrum, and therefore probes of multiple colors can be constructed taking advantage of the $\mathrm{Cu}(\mathrm{II}) / \mathrm{Cu}(\mathrm{I})$ sensing mechanism.

A family of red-fluorescent sensors for $\mathrm{HNO}$ and $\mathrm{NO}$ was recently developed in our laboratory. ${ }^{27}$ These probes, termed CuBRNO1-3, are based on the benzoresorufin fluorophore, which emits 
light at $\lambda_{\mathrm{em}}=625 \mathrm{~nm}$. The copper-binding sites include aminoquinoline (CuBRNO1 and 2) or picolylamine (CuBRNO3) chelating units as well as an exocyclic oxygen atom of the benzoresorufin scaffold (Chart 1).

Chart 1. Structures and photophysical properties of BRNO sensors.

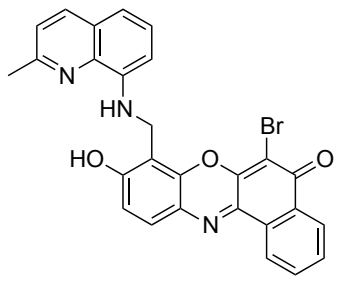

BRN01

$\lambda_{\mathrm{ex}}=570 \mathrm{~nm}$

$\lambda_{\text {em }}=623 \mathrm{~nm}$

$\varepsilon \phi=125 \mathrm{~cm}^{-1} \mathrm{M}^{-1}$
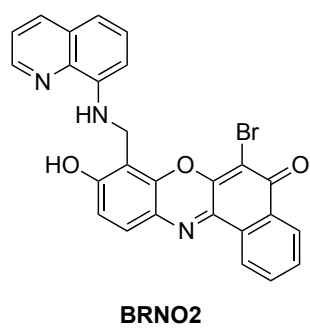

$\lambda_{\mathrm{ex}}=570 \mathrm{~nm}$

$\lambda_{\mathrm{em}}=623 \mathrm{~nm}$

$\varepsilon \phi=103 \mathrm{~cm}^{-1} \mathrm{M}^{-1}$

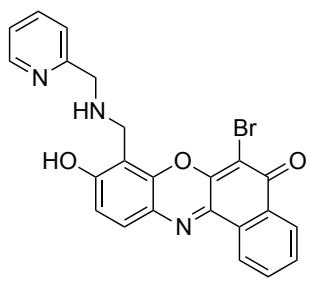

BRNO3

$\lambda_{\mathrm{ex}}=563 \mathrm{~nm}$

$\lambda_{\mathrm{em}}=625 \mathrm{~nm}$

$\varepsilon \phi=2974 \mathrm{~cm}^{-1} \mathrm{M}^{-1}$

Ligands BRNO1 and BRNO2 display absorption maxima at $\lambda_{\mathrm{abs}}=570 \mathrm{~nm}$, with low extinction coefficients of only $2.2 \times 10^{3}$ and $2.1 \times 10^{3} \mathrm{~cm}^{-1} \mathrm{M}^{-1}$, respectively. Emission of these ligands occurs at $\lambda_{\mathrm{em}}=623 \mathrm{~nm}$ with low quantum yields of $\phi=0.055$ for BRNO1 and $\phi=0.048$ for BRNO2. These sub-optimal photophysical properties can be explained based on structural considerations. 8-Aminoquinoline provides an electron rich $\pi$-system that can readily quench the photoexcited state of another fluorophore by ligand-to-ligand charge transfer (LLCT) processes. Time-dependent density functional theoretical (TD-DFT) calculations of BRNO1 at the B3LYP/6-31G(d,p) level of theory reveal that both the $S_{0} \rightarrow S_{1}$ and $S_{0} \rightarrow S_{2}$ vertical transitions have strong LLCT components, ${ }^{27}$ which are potential non-radiative decay pathways of the photoexcited state, with a concomitant low emission quantum yield. In addition, the protonation state of the exocyclic oxygen atom, which serves as an electron donor in the fluorophore, also affects the photophysical properties. The $\mathrm{p} K_{\mathrm{a}}$ associated with protonation of this oxygen atom is $\sim 6.5$ for both BRNO1 and BRNO2, and the ligands are significantly protonated at neutral $\mathrm{pH}$. TD-DFT calculations of the protonated ligand BRNO1 show that the $S_{0} \rightarrow S_{1}$ transition has a very 
low oscillator strength $(f=0.0003)$, suggesting that protonation of the electron donating oxygen atom is responsible for the low extinction coefficients observed experimentally. ${ }^{27}$ In contrast, the picolylamine chelating unit of BRNO3 does not undergo LLCT and the $\mathrm{p} K_{\mathrm{a}}$ of the benzoresorufin fluorophore is 5.9 , which is consistent with a higher experimental extinction coefficient of $1.2 \times 10^{4} \mathrm{~cm}^{-1} \mathrm{M}^{-1}$ and quantum yield of $\phi=0.25$. The photophysical properties of the BRNO ligands illustrate an important design principle of metal-based fluorescent sensors: electron-rich metal chelating units can quench the emission of the fluorophore in the apo state, which reduces dramatically the dynamic range of the probe. In addition, the $\mathrm{p} K_{\mathrm{a}}$ values of electron donors and acceptors in the fluorophore need to be tuned carefully to maximize the dynamic range of the probe at $\mathrm{pH}$ values where the probe will be employed.

All CuBRNO probes react with HNO to give a turn-on fluorescent signal. CuBRNO1 gives the largest response, an $\sim 5$-fold emission enhancement, in aqueous buffer (50 mM PIPES, $100 \mathrm{mM}$ $\mathrm{KCl}, \mathrm{pH}$ 7). The selectivity of the probes, however, is diminished compared to that of CuBOT1. CuBRNO probes turn on in the presence of $\mathrm{NO}(\mathrm{g}) S$-nitrosopenicillin (SNAP), an NO donor. The reactivity of CuBRNOs with NO presumably obeys a reaction mechanism similar to that of NO probes of the $\mathrm{CuFL}^{28}$ and $\mathrm{CuSNFL}^{29}$ families, in which the aminoquinoline ligand is nitrosated upon reaction of the copper complex with NO. ${ }^{30}$ Although the CuBRNO probes are not completely selective, the fluorescent turn-on response of CuBRNO1 to HNO is significantly larger than for $\mathrm{NO}$, and therefore this sensor might be useful for some cell imaging applications.

CuBRNO1 and CuBRNO3 have been used to detect exogenously applied HNO in cultured cells. Live HeLa cells were incubated with $2.5 \mathrm{mM} \mathrm{CuBRNO1}$ and addition of $1 \mathrm{mM}$ Angeli's salt induced a $\sim 4$-fold emission enhancement. ${ }^{27}$ Addition of GSNO to either HeLa or RAW 264.7 
cells loaded with CuBRNO1 gave essentially no turn-on, suggesting that, in cell studies, CuBRNO1 has good selectivity for HNO compared to NO. CuBRNO3 also responded to exogenously applied HNO in both HeLa (Figure 3) or RAW 264.7 cells. $^{27}$

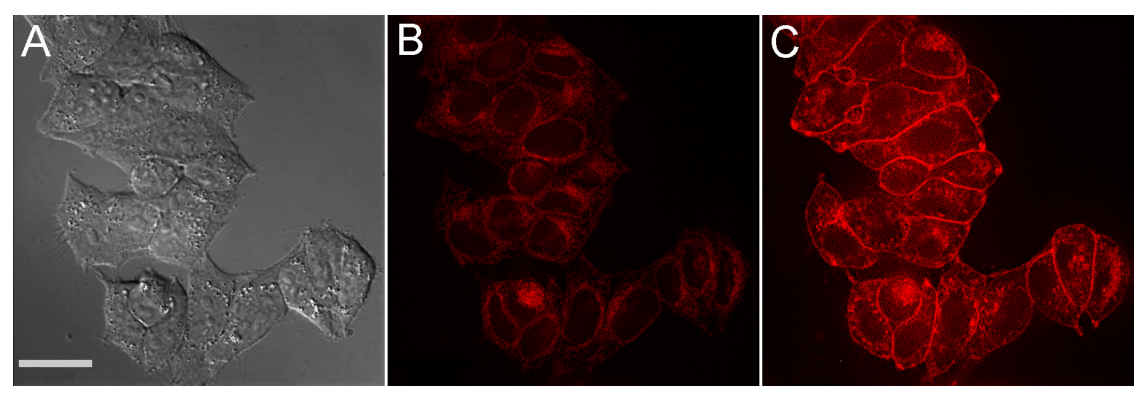

Figure 3. HNO-induced fluorescent turn-on of BRNO3 in live HeLa cells. A) DIC image; B) red channel image before and C) 5 min after treatment with 500 equiv of Angeli's salt. Scale bar = $25 \mu \mathrm{m}$.

\section{Imaging HNO in the Near-Infrared (NIR)}

The most recent member of the family of $\mathrm{Cu}$-based $\mathrm{HNO}$ fluorogenic sensors is the NIRemitting probe $\mathrm{CuDHX} 1 .^{31}$ This complex consists of a cyclam binding site for copper and a dihydroxanthene (DHX) fluorophore. Cyclam is a tetradentate chelating ligand that binds copper, and the reactions between copper cyclam complexes and thiols are slow $\left(t_{1 / 2}>10\right.$ min for $\mathrm{H}_{2} \mathrm{~S} ; t_{1 / 2}$ $>1 \mathrm{~h}$ for glutathione). ${ }^{32}$ The DHX fluorophore was recently introduced by Lin and co-workers ${ }^{33}$ and is available in a single synthetic step from carbocyanine dyes and resorcinol derivatives.

CuDHX1 was prepared by attaching cyclam to a derivative of the DHX fluorophore bearing a chloromethyl substituent (Scheme 3), followed by partial alkylation of the cyclam unit. The photophysical properties of CuDHX1 were measured in aqueous buffer (50 mM PIPES, $100 \mathrm{mM}$ $\mathrm{KCl}, \mathrm{pH}$ 7). The metal-free ligand absorbs light at $\lambda_{\mathrm{abs}}=693 \mathrm{~nm}$ with a high extinction 
coefficient of $2.3 \times 10^{4} \mathrm{~cm}^{-1} \quad \mathrm{M}^{-1}$. This compound emits at $\lambda_{\mathrm{em}}=715$ $\mathrm{nm}$ with a quantum yield of $\phi=0.048$. In the $\mathrm{Cu}$-bound form, the absorption remains essentially identical to that of the free ligand, but the quantum yield decreases to $\phi=0.0027$, demonstrating that the paramagnetic $\mathrm{Cu}(\mathrm{II})$ ion quenches the fluorescence of the DHX fluorophore efficiently.

Scheme 3. Synthesis of NIR ligand DHX1.
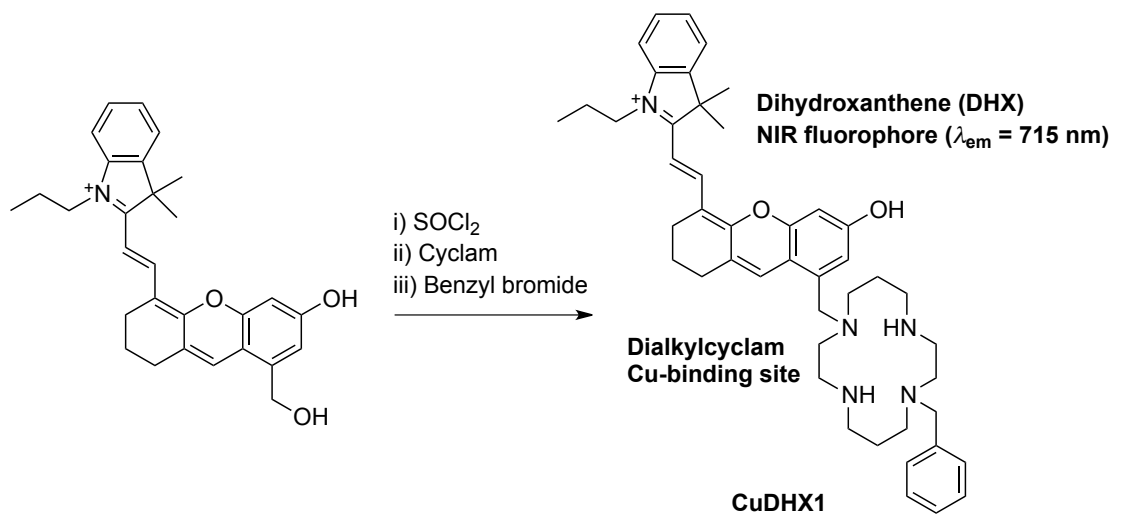

Sensor CuDHX1 is significantly more selective than CuBOT1. No fluorescence enhancement was observed upon treatment of a solution of CuDHX1 with a large excess (100 equiv) of ascorbic acid, cysteine, or glutathione. ${ }^{31}$ Only small and slow $\left(t_{1 / 2} \sim 5 \mathrm{~min}\right)$ reduction of CuDHX1 was observed when treated with excess $\mathrm{Na}_{2} \mathrm{~S}$ in buffered aqueous solution. Under the same conditions, Angeli's salt elicited a fast ( $\left.t_{1 / 2} \sim 1 \mathrm{~min}\right)$ fluorescence turn-on (5-fold).

CuDHX1 has been used to image exogenously applied HNO. The sensor was readily taken up by live cells, and incubation times of only $15 \mathrm{~min}$ sufficed to load the probe to the intracellular space. In live HeLa cells, CuDHX1 showed only faint fluorescence in the NIR channel. Incubation of these cells with 1.5 mM Angeli's salt in PBS led to a 3-fold fluorescence turn-on of $\mathrm{CuDHX} 1$. In contrast, incubation of cells containing $\mathrm{CuDHX} 1$ with $\mathrm{Na}_{2} \mathrm{~S}$ did not lead to any change in the intracellular fluorescence, and treatment of the same cells with Angeli's salt still 
induced a significant turn-on response, ${ }^{31}$ demonstrating that the presence of $\mathrm{H}_{2} \mathrm{~S}$ does not interfere with HNO sensing employing CuDHX1.

NIR probes can be used in combination with those that emit in the visible to perform experiments in which more than one analyte is detected at the same time. ${ }^{25,26}$ The excitation and emission profiles of CuDHX1 do not overlap with those of blue and green fluorescent sensors and this probe is therefore suitable for multicolor/multianalyte experiments. Taking advantage of these properties, CuDHX1 was used to investigate the interplay between exogenously applied HNO and loosely chelated, or mobile, zinc.

The concentration of mobile zinc in the cytoplasm is regulated by metallothioneins, a group of small, cysteine rich proteins that bind heavy metals and play a role in detoxification and redox potential regulation within cells. ${ }^{34}$ Post-translational modifications of cysteine, such as oxidation (disulfide bond formation) and nitrosation, lead to the dissociation of the chelated zinc ${ }^{35,36}$ and potentially to an increase in the concentration of such cations in the cell. NO cannot nitrosate zinc thiolates directly, ${ }^{37}$ but $\mathrm{HNO}$ reacts with thiols to form sulfinamides. ${ }^{2}$ Therefore, a possible downstream effect of exogenously applied HNO is mobilization of zinc from metallothionein or other cysteine-rich, zinc-binding macromolecular stores. By using CuDHX1 and ZP1, a zincselective, green-fluorescent probe ${ }^{38}$ this hypothesis was tested in live HeLa cells (Figure 4). ${ }^{31}$ The two fluorescent sensors, CuDHX1 and ZP1, were loaded into the cells and imaged in the green and NIR channels. HeLa cells normally have cytosolic concentrations of mobile zinc in the picomolar range,,$^{39}$ below the detection limit of $\mathrm{ZP}^{38}$ and, before stimulation, only slight background fluorescence was detected in the green channel (Figure 4C). Addition of Angeli's salt led to fluorescence turn-on both in the NIR and green channels, revealing that the intracellular concentrations of both $\mathrm{HNO}$ and mobile zinc had increased (Figures $4 \mathrm{E}$ and $4 \mathrm{~F}$ ). 
Treatment of the cells with the intracellular zinc chelator $N, N, N^{\prime}, N^{\prime}$-tetrakis(2pyridylmethyl)ethylenediamine (TPEN) reduced the fluorescence intensity in the green channel (Figure 4G), consistent with chelation of the released zinc. This simple experiment established a connection between exogenously applied HNO and mobile zinc in biology, and it also showcased the utility of NIR optical probes in multicolor/multianalyte microscopy experiments.
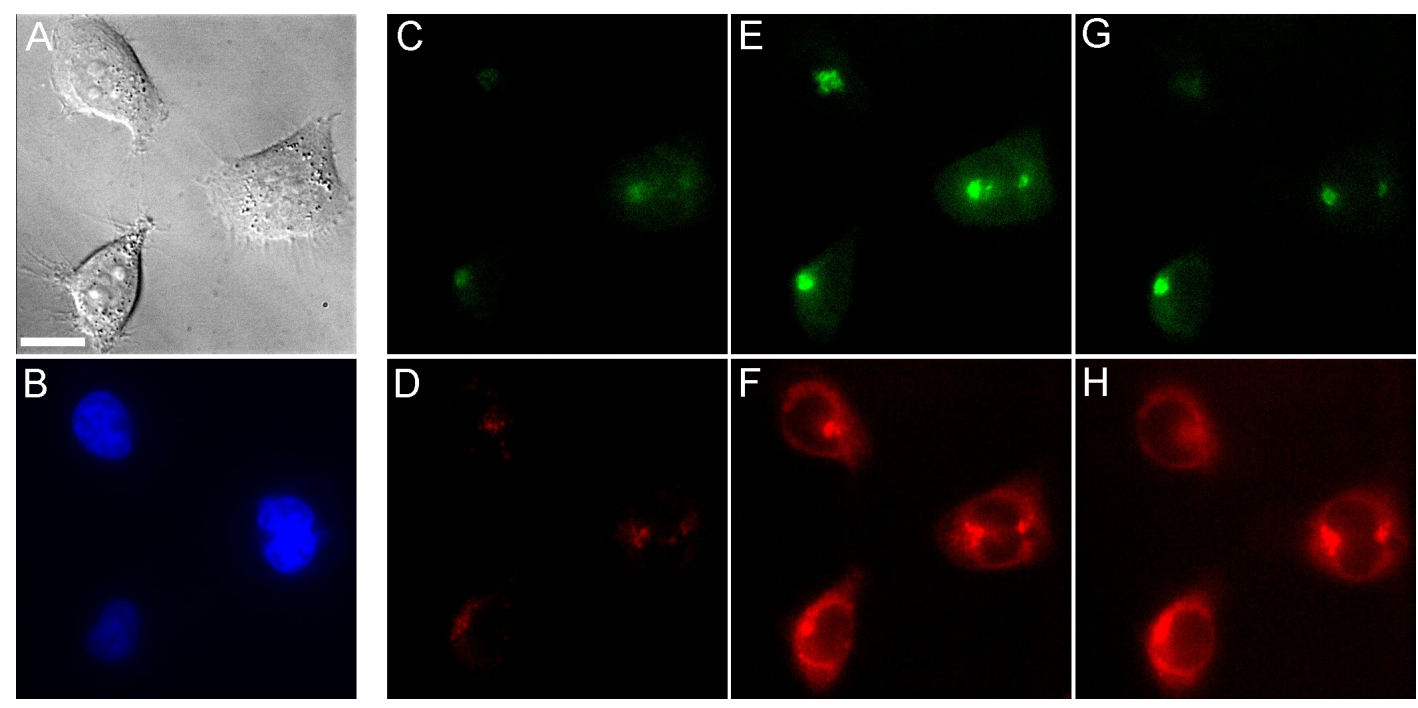

Figure 5. Dual-color imaging of HNO-induced $\mathrm{Zn}^{2+}$ mobilization. A) DIC image of live HeLa cells; B) blue channel showing nuclei stained with Hoechst 33342 dye; C) green channel and D) NIR channel images of the cells before any treatment; E) green channel and F) NIR channel images after treatment with $1.5 \mathrm{mM}$ Angeli's salt; G) green channel and H) NIR channel images after addition of $50 \mathrm{mM}$ TPEN. Scale bar $=10 \mathrm{~mm}$.

\section{Conclusions and Perspectives}

HNO is a short-lived, reactive species that presumably exists in biology only transiently and in small concentrations. Its detection in complex biological samples is therefore challenging. A solution to this problem came from inorganic chemistry, through the creation of copper 
complexes that become fluorescent upon reaction with HNO. Difficulties associated with creating probes that are fast, selective, sensitive, and biocompatible have been overcome, and a series of fluorescent sensors that span the visible and NIR range of emission wavelengths is now available. ${ }^{6,27,31}$ Some of these probes, notably CuBOT1 and CuDHX1, have been used to investigate the generation of HNO in mammalian cells ${ }^{17,19}$ and to explore possible intracellular targets of exogenously applied HNO. ${ }^{21,31}$

Despite the value of the probes described here, more advanced sensors are still needed to investigate details of the biochemistry of HNO. Devising probes that can detect HNO reversibly is particularly challenging but also important for quantitative studies, especially because ratiometric imaging can only report equilibrium concentrations when the sensing event is reversible. Reversibility may be achieved by using fluorogenic metal complexes with reduction potentials tuned to bind HNO without oxidizing it to NO. With reversible sensors in hands, ratiometric imaging employing a second fluorophore could be realized.

Investigation of the intracellular sources and targets of HNO would benefit from the preparation of sensors that can target discrete subcellular locales. Strategies to label particular cellular organelles include genetically encoded fusion protein tags, ${ }^{40-42}$ synthetic peptides, ${ }^{43-46}$ and smallmolecule vectors ${ }^{47-49}$ to deliver HNO sensors to programmed locations within the cell.

The availability of NIR-emitting sensors for HNO opens the possibility of multicolor/multianalyte microscopic studies. In addition, these probes might be applied to detect HNO in thicker specimens, such as acute tissue slices and even live animals, potentially leading to the establishment of links between HNO and physiological or pathological conditions in whole organisms. 


\section{AUTHOR INFORMATION}

\section{Corresponding Author}

*lippard@mit.edu.

\section{Notes}

The authors declare no competing financial interests.

\section{Biographies}

Stephen J. Lippard is the Arthur Amos Noyes Professor of Chemistry at the Massachusetts Institute of Technology. His research areas lie at the interface of inorganic chemistry and biology.

Pablo Rivera-Fuentes received his $\mathrm{PhD}$ in Chemistry from ETH Zurich under the supervision of François Diederich. He was a postdoctoral fellow with Stephen J. Lippard at the Massachusetts Institute of Technology (2012-2014). Since 2015 he is Assistant Professor of Organic Chemistry at ETH Zurich.

\section{ACKNOWLEDGMENTS}

This work was supported by a grant from the National Science Foundation. P. R.-F. thanks the Swiss National Science Foundation for a postdoctoral fellowship.

\section{REFERENCES}

1. Bullen, M. L.; Miller, A. A.; Andrews, K. L.; Irvine, J. C.; Ritchie, R. H.; Sobey, C. G.; Kemp-Harper, B. K. Nitroxyl (HNO) as a Vasoprotective Signaling Molecule. Antioxid. Redox Signal. 2011, 14, 1675-1686. 
2. Fukuto, J. M.; Carrington, S. J. HNO Signaling Mechanisms. Antiox. Redox Signal. 2011, $14,1649-1657$.

3. Doctorovich, F.; Bikiel, D. E.; Pellegrino, J.; Suárez, S. A.; Martí, M. A. How to Find an HNO Needle in a (Bio)-Chemical Haystack. In Progress in Inorganic Chemistry; Karlin, K. D., Ed.; 2014; Vol. 58; pp 145-183.

4. Tennyson, A. G.; Do, L.; Smith, R. C.; Lippard, S. J. Selective Fluorescence Detection of Nitroxyl over Nitric Oxide in Buffered Aqueous Solution using a Conjugated Metallopolymer. Polyhedron 2007, 26, 4625-4630.

5. Miranda, K. M.; Nagasawa, H. T.; Toscano, J. P. Donors of HNO. Curr. Top. Med. Chem. 2005, 5, 649-664.

6. Rosenthal, J.; Lippard, S. J. Direct Detection of Nitroxyl in Aqueous Solution Using a Tripodal Copper(II) BODIPY Complex. J. Am. Chem. Soc. 2010, 132, 5536-5537.

7. Huisgen, R. Centenary Lecture - 1,3-Dipolar Cycloadditions. Proc. Chem. Soc. 1961, 357369.

8. Kolb, H. C.; Finn, M. G.; Sharpless, K. B. Click Chemistry: Diverse Chemical Function from a Few Good Reactions. Angew. Chem. Int. Ed. 2001, 40, 2004-2021.

9. Zhou, Y.; Liu, K.; Li, J.-Y.; Fang, Y.; Zhao, T.-C.; Yao, C. Visualization of Nitroxyl in Living Cells by a Chelated Copper(II) Coumarin Complex. Org. Lett. 2011, 13, 12901293. 
10. Lakowicz, J. R.; Szmacinski, H.; Nowaczyk, K.; Berndt, K. W.; Johnson, M. Fluorescence Lifetime Imaging. Anal. Biochem. 1992, 202, 316-330.

11. Royzen, M.; Wilson, J. J.; Lippard, S. J. Physical and Structural Properties of $[\mathrm{Cu}(\mathrm{BOT} 1) \mathrm{Cl}] \mathrm{Cl}$, a Fluorescent Imaging Probe for HNO. J. Inorg. Biochem. 2013, 118, 162-170.

12. Murphy, M. E.; Sies, H. Reversible Conversion of Nitroxyl Anion to Nitric Oxide by Superoxide Dismutase. Proc. Natl. Acad. Sci. U. S. A. 1991, 88, 10860-10864.

13. Armstrong, D. A.; Huie, R. E.; Lymar, S.; Koppenol, W. H.; Merényi, G.; Neta, P.; Stanbury, D. M.; Steenken, S.; Wardman, P. Standard Electrode Potentials Involving Radicals in Aqueous Solution: Inorganic Radicals. BioInorg. React. Mech. 2014, 9, 59-61.

14. Lee, K. Y.; Kuchynka, D. J.; Kochi, J. K. Redox Equilibria of the Nitrosonium Cation and of its Nonbonded Complexes. Inorg. Chem. 1990, 29, 4196-4204.

15. Michael, M. A.; Pizzella, G.; Yang, L.; Shi, Y.; Evangelou, T.; Burke, D. T.; Zhang, Y. $\mathrm{HNO} / \mathrm{NO}$ Conversion Mechanisms of Cu-Based HNO Probes with Implications for $\mathrm{Cu}$, Zn-SOD. J. Phys. Chem. Lett. 2014, 5, 1022-1026.

16. Manders, E. M. M.; Verbeek, F. J.; Aten, J. A. Measurement of Co-localization of Objects in Dual-Color Confocal Images. J. Microsc. 1993, 169, 375-382.

17. Filipovic, M. R.; Miljkovic, J. L.; Nauser, T.; Royzen, M.; Klos, K.; Shubina, T.; Koppenol, W. H.; Lippard, S. J.; Ivanović-Burmazović, I. Chemical Characterization of the Smallest S-Nitrosothiol, HSNO; Cellular Cross-talk of $\mathrm{H}_{2} \mathrm{~S}$ and S-Nitrosothiols. J. Am. Chem. Soc. 2012, 134, 12016-12027. 
18. Filipovic, M. R.; Eberhardt, M.; Prokopovic, V.; Mijuskovic, A.; Orescanin-Dusic, Z.; Reeh, P.; Ivanovic-Burmazovic, I. Beyond $\mathrm{H}_{2} \mathrm{~S}$ and NO Interplay: Hydrogen Sulfide and Nitroprusside React Directly to Give Nitroxyl (HNO). A New Pharmacological Source of HNO. J. Med. Chem. 2013, 56, 1499-1508.

19. Miljkovic, J. L.; Kenkel, I.; Ivanović-Burmazović, I.; Filipovic, M. R. Generation of HNO and HSNO from Nitrite by Heme-Iron-Catalyzed Metabolism with $\mathrm{H}_{2} \mathrm{~S}$. Angew. Chem. Int. Ed. 2013, 52, 12061-12064.

20. Heinecke, J. L.; Khin, C.; Melo Pereira, J. C.; Suárez, S. A.; Iretskii, A. V.; Doctorovich, F.; Ford, P. C. Nitrite Reduction Mediated by Heme Models. Routes to NO and HNO? J. Am. Chem. Soc. 2013, 135, 4007-4017.

21. Eberhardt, M.; Dux, M.; Namer, B.; Miljkovic, J.; Cordasic, N.; Will, C.; Kichko, T. I.; de la Roche, J.; Fischer, M.; Suárez, S. A.; Bikiel, D.; Dorsch, K.; Leffler, A.; Babes, A.; Lampert, A.; Lennerz, J. K.; Jacobi, J.; Martí, M. A.; Doctorovich, F.; Högestatt, E. D.; Zygmunt, P. M.; Ivanovic-Burmazovic, I.; Messlinger, K.; Reeh, P.; Filipovic, M. R. $\mathrm{H}_{2} \mathrm{~S}$ and NO Cooperatively Regulate Vascular Tone by Activating a Neuroendocrine HNOTRPA1-CGRP Signalling Pathway. Nat. Commun. 2014, 5, DOI: 10.1038/ncomms5381.

22. Hinman, A.; Chuang, H.-h.; Bautista, D. M.; Julius, D. TRP Channel Activation by Reversible Covalent Modification. Proc. Natl. Acad. Sci. U. S. A. 2006, 103, 19564-19568.

23. Paolocci, N.; Saavedra, W. F.; Miranda, K. M.; Martignani, C.; Isoda, T.; Hare, J. M.; Espey, M. G.; Fukuto, J. M.; Feelisch, M.; Wink, D. A.; Kass, D. A. Nitroxyl Anion Exerts Redox-Sensitive Positive Cardiac Inotropy in Vivo by Calcitonin Gene-Related Peptide Signaling. Proc. Natl. Acad. Sci. U. S. A. 2001, 98, 10463-10468. 
24. Hilderbrand, S. A.; Weissleder, R. Near-Infrared Fluorescence: Application to in vivo Molecular Imaging. Curr. Op. Chem. Biol. 2010, 14, 71-79.

25. Egawa, T.; Hirabayashi, K.; Koide, Y.; Kobayashi, C.; Takahashi, N.; Mineno, T.; Terai, T.; Ueno, T.; Komatsu, T.; Ikegaya, Y.; Matsuki, N.; Nagano, T.; Hanaoka, K. Red Fluorescent Probe for Monitoring the Dynamics of Cytoplasmic Calcium Ions. Angew. Chem. Int. Ed. 2013, 52, 3874-3877.

26. Kobayashi, H.; Koyama, Y.; Barrett, T.; Hama, Y.; Regino, C. A. S.; Shin, I. S.; Jang, B.S.; Le, N.; Paik, C. H.; Choyke, P. L.; Urano, Y. Multimodal Nanoprobes for Radionuclide and Five-Color Near-Infrared Optical Lymphatic Imaging. ACS Nano 2007, 1, 258-264.

27. Apfel, U.-P.; Buccella, D.; Wilson, J. J.; Lippard, S. J. Detection of Nitric Oxide and Nitroxyl with Benzoresorufin-Based Fluorescent Sensors. Inorg. Chem. 2013, 52, 32853294.

28. Lim, M. H.; Xu, D.; Lippard, S. J. Visualization of Nitric Oxide in Living Cells by a Copper-Based Fluorescent Probe. Nat. Chem. Biol. 2006, 2, 375-380.

29. Pluth, M. D.; Chan, M. R.; McQuade, L. E.; Lippard, S. J. Seminaphthofluorescein-Based Fluorescent Probes for Imaging Nitric Oxide in Live Cells. Inorg. Chem. 2011, 50, 93859392.

30. McQuade, L. E.; Pluth, M. D.; Lippard, S. J. Mechanism of Nitric Oxide Reactivity and Fluorescence Enhancement of the NO-Specific Probe CuFL1. Inorg. Chem. 2010, 49, 8025-8033. 
31. Wrobel, A. T.; Johnstone, T. C.; Liang, A. D.; Lippard, S. J. Rivera-Fuentes, P.: A Fast and Selective Near-Infrared Fluorescent Sensor for Multicolor Imaging of Biological Nitroxyl (HNO). J. Am. Chem. Soc. 2014, 136, 4697-4705.

32. Sasakura, K.; Hanaoka, K.; Shibuya, N.; Mikami, Y.; Kimura, Y.; Komatsu, T.; Ueno, T.; Terai, T.; Kimura, H.; Nagano, T. Development of a Highly Selective Fluorescence Probe for Hydrogen Sulfide. J. Am. Chem. Soc. 2011, 133, 18003-18005.

33. Yuan, L.; Lin, W.; Zhao, S.; Gao, W.; Chen, B.; He, L.; Zhu, S. A Unique Approach to Development of Near-Infrared Fluorescent Sensors for in Vivo Imaging. J. Am. Chem. Soc . 2012, 134, 13510-13523.

34. Coyle, P.; Philcox, J. C.; Carey, L. C.; Rofe, A. M. Metallothionein: The Multipurpose Protein. Cell. Mol. Life Sci. 2002, 59, 627-647.

35. Berendji, D.; Kolb-Bachofen, V.; Meyer, K. L.; Grapenthin, O.; Weber, H.; Wahn, V.; Kröncke, K.-D. Nitric Oxide Mediates Intracytoplasmic and Intranuclear Zinc Release. FEBS Lett. 1997, 405, 37-41.

36. Stamler, J. S.; Simon, D. I.; Osborne, J. A.; Mullins, M. E.; Jaraki, O.; Michel, T.; Singel, D. J.; Loscalzo, J. S-Nitrosylation of Proteins with Nitric Oxide: Synthesis and Characterization of Biologically Active Compounds. Proc. Natl. Acad. Sci. U. S. A. 1992, $89,444-448$.

37. Kozhukh, J.; Lippard, S. J. Zinc Thiolate Reactivity toward Nitrogen Oxides: Insights into the Interaction of $\mathrm{Zn}^{2+}$ with $S$-Nitrosothiols and Implications for Nitric Oxide Synthase. Inorg. Chem. 2012, 51, 7346-7353. 
38. Burdette, S. C.; Walkup, G. K.; Spingler, B.; Tsien, R. Y.; Lippard, S. J. Fluorescent Sensors for $\mathrm{Zn}^{2+}$ based on a Fluorescein Platform: Synthesis, Properties and Intracellular Distribution. J. Am. Chem. Soc. 2001, 123, 7831-7841.

39. Qin, Y.; Miranda, J. G.; Stoddard, C. I.; Dean, K. M.; Galati, D. F.; Palmer, A. E. Direct Comparison of a Genetically Encoded Sensor and Small Molecule Indicator: Implications for Quantification of Cytosolic $\mathrm{Zn}^{2+}$. ACS Chem. Biol. 2013, 8, 2366-2371.

40. Gautier, A.; Juillerat, A.; Heinis, C.; Corrêa, I. R., Jr.; Kindermann, M.; Beaufils, F.; Johnsson, K. An Engineered Protein Tag for Multiprotein Labeling in Living Cells. Chem. Biol. 2008, 15, 128-136.

41. Keppler, A.; Gendreizig, S.; Gronemeyer, T.; Pick, H.; Vogel, H.; Johnsson, K. A General Method for the Covalent Labeling of Fusion Proteins with Small Molecules in Vivo. Nat. Biotechnol. 2003, 21, 86-89.

42. Los, G. V.; Encell, L. P.; McDougall, M. G.; Hartzell, D. D.; Karassina, N.; Zimprich, C.; Wood, M. G.; Learish, R.; Friedman Ohane, R.; Urh, M.; Simpson, D.; Mendez, J.; Zimmerman, K.; Otto, P.; Vidugiris, G.; Zhu, J.; Darzins, A.; Klaubert, D. H.; Bulleit, R. F.; Wood, K. V. HaloTag: A Novel Protein Labeling Technology for Cell Imaging and Protein Analysis. ACS Chem. Biol. 2008, 3, 373-382.

43. Horton, K. L.; Stewart, K. M.; Fonseca, S. B.; Guo, Q.; Kelley, S. O. MitochondriaPenetrating Peptides. Chem. Biol. 2008, 15, 375-382.

44. Stornaiuolo, M.; Lotti, L. V.; Borgese, N.; Torrisi, M.-R.; Mottola, G.; Martire, G.; Bonatti, S. KDEL and KKXX Retrieval Signals Appended to the Same Reporter Protein 
Determine Different Trafficking Between Endoplasmic Reticulum, Intermediate Compartment, and Golgi Complex. Mol. Biol. Cell 2003, 14, 889-902.

45. Vivès, E.; Brodin, P.; Lebleu, B. A Truncated HIV-1 Tat Protein Basic Domain Rapidly Translocates through the Plasma Membrane and Accumulates in the Cell Nucleus. J. Biol. Chem. 1997, 272, 16010-16017.

46. Wender, P. A.; Mitchell, D. J.; Pattabiraman, K.; Pelkey, E. T.; Steinman, L.; Rothbard, J. B. The Design, Synthesis, and Evaluation of Molecules that Enable or Enhance Cellular Uptake: Peptoid Molecular Transporters. Proc. Natl. Acad. Sci. U. S. A. 2000, 97, 1300313008.

47. Hambrock, A.; Löffler-Walz, C.; Quast, U. Glibenclamide Binding to Sulphonylurea Receptor Subtypes: Dependence on Adenine Nucleotides. Brit. J. Pharmacol. 2002, 136, 995-1004.

48. Pagano, R. E.; Martin, O. C.; Kang, H. C.; Haugland, R. P. A Novel Fluorescent Ceramide Analog for Studying Membrane Traffic in Animal Cells: Accumulation at the Golgi Apparatus Results in Altered Spectral Properties of the Sphingolipid Precursor. J. Cell Biol. 1991, 113, 1267-1279.

49. Ross, M. F.; Kelso, G. F.; Blaikie, F. H.; James, A. M.; Cochemé, H. M.; Filipovska, A.; Da Ros, T.; Hurd, T. R.; Smith, R. A. J.; Murphy, M. P. Lipophilic Triphenylphosphonium Cations as Tools in Mitochondrial Bioenergetics and Free Radical Biology. Biochemistry (Moscow) 2005, 70, 222-230. 


\section{Conspectus Graphic}

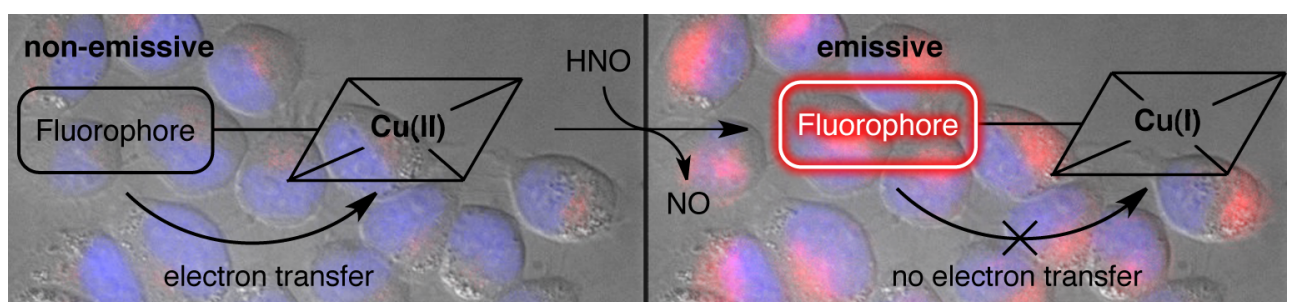

